\title{
Expression of Functional Interleukin 2 Receptors by Peripheral Blood Monocytes from Patients with Active Pulmonary Tuberculosis
}

Zahra Toossi, John R. Sedor, John P. Lapurga, Robert J. Ondash, and Jerrold J. Ellner

Department of Medicine, Case Western Reserve University, and Veterans Administration Medical Center and University Hospitals of Cleveland, Cleveland, Ohio 44106

\begin{abstract}
Peripheral blood monocytes from patients with active tuberculosis are "activated" by a number of criteria, including selective depression of T-lymphocyte responses to the mycobacterial antigen, tuberculin-purified protein derivative (PPD). We studied monocytes from patients with tuberculosis and healthy skin test reactive controls for expression and function of IL 2 receptors (IL 2R). Depletion of adherent monocytes increased the IL 2 activity of supernatants of PPD-stimulated $T$ cell cultures from patients by 30 -fold. When cultured with purified IL 2, adherent cells from the patients depleted IL 2 activity by 66\%. Monocytes from patients displayed IL $2 R$ on their surface as evidenced by anti-Tac reactivity, and released soluble IL 2R into the medium during culture. The release of soluble IL 2R was augmented when monocytes were cultured with PPD. Finally, freshly isolated adherent monocytes from patients but not healthy individuals expressed the gene encoding Tac protein. Thus, blood monocytes from patients with tuberculosis express functional IL $2 \mathrm{R}$ constitutively. This property may be important in the immunoregulatory and effector function of mononuclear phagocytes during tuberculosis. (J. Clin. Invest. 1990. 85:1777-1784.) monocyte • IL 2R • tuberculosis
\end{abstract}

\section{Introduction}

Blood monocytes from patients with pulmonary tuberculosis (TB) ${ }^{1}$ show a number of stigmata of activation. Such cells display increased stimulated release of IL 1 (1), augmented adherence to plastic (2), enhanced hexose monophosphate shunt activity (3), altered surface expression of HLA DR antigens (4), and increased killing of some but not all targets (5). Circulating monocytes from patients with TB also selectively depress lymphocyte responses to the mycobacterial antigen, tuberculin purified protein derivative (PPD) $(6,7)$; this activity may contribute to depression of delayed-type hypersensitivity (DTH), as assessed by tuberculin skin tests in such patients. The expression of cell-mediated immune response requires the interaction of IL 2 with its receptor (IL 2R) on the surface of antigen-responsive $T$ cells (8). IL $2 R$ also have been demon-

Received for publication 17 January 1989 and in revised form 17 January 1990.

1. Abbreviations used in this paper: APAAP, alkaline phosphatase anti-alkaline phosphatase; IFN, interferon gamma; IL 1, interleukin1; IL 2, interleukin-2, IL 2R, interleukin-2 receptor; PBMC, peripheral blood mononuclear cells; PPD, purified protein derivative; TB, tuberculosis.

The Journal of Clinical Investigation, Inc.

Volume 85, June 1990, 1777-1784 strated on the surface of B cells, and their expression can be induced on human monocytes (9-12). In sarcoidosis, a chronic granulomatous disease characterized by infiltration of the lungs with activated mononuclear cells, bronchoalveolar macrophages express IL $2 R$ (13). We previously have shown depressed T cell expression of IL 2 in patients with active pulmonary TB, in part related to modulatory effects of monocytes (7). Monocytes may down regulate $T$ cell synthesis of IL 2 and/or increase its consumption. The latter is a possibility since enhanced IL 2 absorption by lymphokine activated human myelomonocytic cells, U937 has been demonstrated (9). The biological consequences of IL $2 R$ expression by mononuclear phagocytes, particularly as regards immunoregulation are unclear.

The high affinity $\left(K_{d}=10^{-11}\right)$ IL $2 R$ on the surface of activated human mononuclear cells consist of two polypeptide chains ( $\alpha$ and $\beta$ ) which confer the efficient binding of IL 2 to the receptor with subsequent activation of immunologic function (14). The more recently described $\alpha$ chain $\left(M_{\mathrm{r}}=75,000\right)$, binds IL 2 sluggishly, however, with an intermediate affinity $\left(K_{d}=10^{-9}\right)$; and while its occupation by the ligand leads to signal transduction, this only occurs at nonphysiologically high levels of IL 2 (15). The $\beta$ chain, also known as Tac protein $\left(M_{\mathrm{r}}=55,000\right)$, reacts with IL 2 more rapidly but with a low affinity $\left(K_{d}=10^{-8}\right)(16)$. A soluble released form of the $\beta$ chain $\left(M_{\mathrm{r}}=45,000\right)$ has been described in several pathologic states $(17-19)$ and in supernatants of lectin activated mononuclear cells (20). The mechanism of release of soluble IL $2 R$ is presently under study; however since soluble IL $2 R$ retain IL 2 binding capacity (21), they may have an immunomodulatory role in disease states.

In the present study we evaluated the expression and function of IL 2R on blood monocytes obtained from patients with TB. Freshly isolated adherent monocytes from patients with newly diagnosed pulmonary TB displayed IL $2 R$ constitutively and such receptors were functional. These monocytes also expressed the gene for the $\beta$ chain of IL $2 \mathrm{R}$. Additionally, mycobacterial products induced IL $2 \mathrm{R}$ gene expression of monocytes from a healthy tuberculin nonreactor. Monocytes cultured from patients with TB released soluble IL $2 R$ into their supernatants, a process augmented by tuberculin PPD. Both the enhanced expression of IL $2 R$ on monocytes and increased release of soluble IL $2 R$ may modulate $T$ cell responsiveness in human TB.

\section{Methods}

Study population. Patients with newly diagnosed active pulmonary tuberculosis hospitalized at Cleveland Veterans Administration Hospital, University Hospitals of Cleveland, and Cleveland Metropolitan General Hospital were studied. Patients with factors potentially affecting the immune response were excluded: $(a)$ age $>65 \mathrm{yr},(b)$ anti-tuberculosis therapy for $>21 \mathrm{~d}$, (c) concomitant debilitating diseases, 
and (d) positive serology for HIV. Diagnosis of TB was based on the demonstration of acid fast bacilli in sputum and was eventually confirmed by positive culture for Mycobacterium tuberculosis. Chest roentgenograms of each patient obtained close to the time of study were graded for extent of tuberculosis according to National Tuberculosis and Respiratory Disease Association criteria (22). Of a total of 25 patients studied, one patient had minimal disease, 16 patients had moderately advanced, and eight patients had far advanced disease. Miliary TB was not seen. A group of healthy tuberculin reactors, age and sex-matched to the patients, was studied concurrently. Additionally, three healthy tuberculin nonreactors and three patients with pulmonary infection by mycobacteria other than $M$. tuberculosis were studied. Informed consent was obtained from all patients and control subjects.

Preparation of cells. $50 \mathrm{ml}$ of heparinized blood $(20 \mathrm{U} / \mathrm{ml})$ was obtained from each subject by venipuncture. Peripheral blood mononuclear cells (PBMC) were separated by sedimentation on Ficoll-Hypaque (Pharmacia Fine Chemicals, Piscataway, NJ) gradients (23). The monocyte content of PBMC was determined by peroxidase cytochemistry (24). PBMC $\left(5 \times 10^{6} / \mathrm{ml}\right)$ were resuspended in RPMI 1640 (MA Bioproducts, Walkersville, MA) supplemented with $10 \%$ (vol/ vol) heat inactivated human $\mathrm{AB}$ serum (Gibco Laboratories, Grand Island, NY) and incubated at $37^{\circ}$ for $1 \mathrm{~h}$ on plastic petri dishes (100 $\times 20 \mathrm{~mm}$; Falcon Labware, Oxnard, CA), which had been precoated with $\mathrm{AB}$ serum. After removing nonadherent cells, the adherent monolayers were dislodged by gentle scraping with a rubber policeman. The resultant adherent cell population consisted of $85-95 \%$ monocytes (peroxidase staining) and was $99 \%$ viable by trypan-blue dye exclusion. The adherent cells were $>85 \%$ LeuM 3 (monocyte/macrophage; Becton Dickinson, Mountainview, CA) reactive and 5-8\% OKT3 (Pan T cell; Orthodiagnostics Inc., Raritan, NJ) positive. In some experiments adherent cells were further depleted of contaminating CD3 $\mathrm{T}$ cells by complement lysis. 5 million adherent cells were incubated with $5 \mu \mathrm{l}$ of OKT3 for $30 \mathrm{~min}$ at room temperature. Baby rabbit complement (Cedarlane, Hornby, Ontario, Canada) at a dilution of 1:4 then was added and the cells incubated for another $30 \mathrm{~min}$. Washed cells were $<1 \%$ OKT3 reactive.

Nonadherent cells were washed onto $600 \mathrm{mg}$ acid-treated nylon wool columns and incubated at $37^{\circ} \mathrm{C}$ for $30 \mathrm{~min}$. The lymphocytes then eluted were $\mathrm{T}$ cell enriched ( $>85 \%$ sheep erythrocyte rosetting) and monocyte depleted $(<1 \%$ peroxidase positive in both patients and healthy donors), and will be referred to as $\mathrm{T}$ cells.

Generation of IL 2-containing supernatants. PBMC or T cells were incubated in 24-well plates (Falcon Labware) at $3 \times 10^{6} / \mathrm{ml}$ in RPMI 1640 supplemented with L-glutamine $(2 \mathrm{mM})$, penicillin $(50 \mathrm{U} / \mathrm{ml})$, gentamicin $(50 \mu \mathrm{g} / \mathrm{ml})$, and $2 \%(\mathrm{vol} / \mathrm{vol}) \mathrm{AB}$ serum. PPD, a gift of Lederle Laboratories (American Cyanamid Co., Wayne, NJ) was added to cell cultures at a final concentration of $100 \mu \mathrm{g} / \mathrm{ml}$. This concentration was found to be optimal for IL 2 generation in a group of healthy donors. After $48 \mathrm{~h}$, supernatants were separated from cells by centrifugation at $500 \mathrm{~g}$ for $10 \mathrm{~min}$ and stored at $-20^{\circ} \mathrm{C}$ until assayed.

Generation of adherent cell supernatants. Adherent cells were washed and resuspended in RPMI 1640 and $2 \%$ (vol/vol) AB serum at $1 \times 10^{6} / \mathrm{ml}$ in 24-well plates. Cultures were carried out in the absence or presence of purified IL 2 (Electronucleonics, Columbia, MD). This preparation of IL 2 is delectinized with no detectable interferon gamma or endotoxin activity and contains $640 \mathrm{U}$ (BRMP)/ml of IL 2 activity.

IL 2 assay. The IL 2 dependent cytotoxic murine $\mathrm{T}$ cell line CTLL-20 was used for assay purposes (25). CTLL-20 cells were washed extensively, and resuspended in DME (MA Bioproducts) at $10^{5} / \mathrm{ml}$. $100 \mu$ l of the cell suspension was placed in flat bottom microtiter wells (Falcon Labware) along with $100 \mu l$ of supernatants in several dilutions. IL 2 determination was performed in triplicate. The total duration of culture was $24 \mathrm{~h} ; 1 \mu \mathrm{Ci}$ of $\left[{ }^{3} \mathrm{H}\right]$ thymidine specific activity 6.7 $\mathrm{Ci} / \mathrm{mmol}$ (ICN Radiochemicals, Irvine, $\mathrm{CA}$ ) was added per well for the last $5 \mathrm{~h}$ of culture. Cells then were harvested and ${ }^{3} \mathrm{H}$ activity was assayed by liquid scintillation spectrometry. Results were analyzed by the probit method (26) using a standard IL 2 supernatant. This preparation of IL 2 is obtained from a gibbon cell line (MLA 144), a constitutive producer of IL 2 . The standard contained $30 \mathrm{U} / \mathrm{ml}$ of activity in our assay.

Quantitation of $I L 2$ receptors. The monoclonal antibody anti-Tac (27) reacts with the $\beta$ chain of human IL $2 R$ and was a generous gift of Dr. T. Waldmann (National Cancer Institute), and it was used at 1:1,000 dilution. Reactivity to anti-Tac antibody was assessed by two methods: FACS analysis or alkaline phosphatase anti-alkaline phosphatase (APAAP) cytostaining (28). In the first, $0.5 \times 10^{6}$ adherent cells were incubated with $50 \mu \mathrm{l}$ of the antibody at $4^{\circ} \mathrm{C}$ for $30 \mathrm{~min}$. Washed cells were further incubated with fluorescein isothiocyanate conjugated anti-mouse IgG (Cappel Laboratories, Malvern, PA) at 1:20 dilution and analyzed on an EPICS V fluorescence activated cell sorter (FACS). Alternatively, adherent cells $\left(0.3 \times 10^{6} / \mathrm{ml}\right)$ were cytocentrifuged onto glass slides. Cells were fixed in $100 \%$ acetone for 3 min and then incubated overnight at $4^{\circ} \mathrm{C}$ with the appropriate dilution of the monoclonal antibody or control antibody, mouse IgG in ascites (Pico Immunochemical Inc., Richmond Heights, $\mathrm{OH}$ ). Cells were then incubated with alkaline phosphatase linked rabbit anti-mouse IgG antiserum (Z-259; Dako Corp., Santa Barbara, CA) (1:10) for 30 min followed by incubation with alkaline phosphatase anti-alkaline phosphatase (D651, Dako Corp.) at 1:25 for $30 \mathrm{~min}$. Slides were washed extensively in Tris-saline buffer $(0.1 \mathrm{M}, \mathrm{pH} 7.6)$ between incubations. Substrate solution (0.1 M Tris buffer, $\mathrm{pH} 8.2,2 \%$ formamide, $0.2 \%$ Naphtol AS-MX, 0.1\% Fast Red and $1 \mathrm{nM}$ Levamisole) was then added for $15 \mathrm{~min}$. Levamisole inhibits endogenous alkaline phosphatase enzyme activity. Slides were then counterstained with Gill's hemotoxylin and mounted. Duplicate slides from each experiment were evaluated microscopically and 200 cells were scored on each slide. In some experiments anti-IL 2R antibody (2A3; Becton Dickinson) was used instead of anti-Tac at a 1:10 dilution. This monoclonal antibody recognizes a different epitope of the Tac protein than anti-Tac antibody.

IL 2 binding assay. The binding of radioiodinated IL 2 to adherent cells was measured according to the method described by Robb et al. (29). ${ }^{125}$ I-labeled human recombinant (r) IL 2 was purchased (NEX 229, specific activity $36.6 \mu \mathrm{Ci} / \mu \mathrm{g}$; New England Nuclear, Boston, MA; DuPont Co., Wilmington, DE). Nonspecific binding was determined by addition of a 200 -fold molar excess of unlabeled rIL 2 (generous gift of Hoffmann La Roche, Nutley, NJ). Briefly, $0.5 \times 10^{6}$ cells were suspended in $100 \mu \mathrm{l}$ of RPMI $164010 \%$ (vol/vol) FCS containing ${ }^{125} \mathrm{I}-\mathrm{IL} 2$ in $1.5 \mathrm{ml}$ Eppendorf micro test tubes (Brinkmann Instruments Co., Westbury, NY) and incubated for $60 \mathrm{~min}$ at $37^{\circ} \mathrm{C}$. Cells were centrifuged for $15 \mathrm{~s}$ at $20,000 \mathrm{~g}$ and resuspended in $100 \mu \mathrm{l}$ of media. The cell suspension was centrifuged through a 150- $\mu$ layer of a mixture of $84 \%$ silicone oil (550 fluids; Contour Chemical Co, North Reading, MA) and 16\% Paraffin oil (Fisher Scientific Co., Pittsburgh, PA) for 2 min at $10,000 \mathrm{~g}$. The tips of the tubes containing the cell pellets were then cut and radioactivity was measured in a gamma counter (Beckman Instruments Inc., Irvine, CA). All binding data were evaluated by the LIGAND program (30).

Measurement of soluble $I L 2 R$. Soluble IL $2 \mathrm{R}$ levels in supernatants was measured with a sandwich enzyme immunoassay (Cell Free, interleukin-2 receptor test kit; T-cell Sciences, Cambridge, MA) (19) according to the manufacturers. Supernatants of adherent cell or standards were added to anti-IL $2 \mathrm{R}$ monoclonal antibody coated microtiter plates in duplicates. An enzyme-conjugated anti-IL 2R monoclonal antibody directed against a second epitope of the IL $2 R$ molecule was added followed by addition of substrate. Absorption was read at $490 \mathrm{~nm}$ with a microelisa plate reader. A standard curve was prepared using the IL 2R standards. Unknown values were determined from the standard curve.

Preparation of RNA. Total RNA was extracted from T cells (20-30 $\left.\times 10^{6}\right)$ or adherent monocytes $\left(10 \times 10^{6}\right)$ by the guanidinium-cesium method as previously described (31). Briefly, cells were washed and pellets were homogenized in $4 \mathrm{M}$ guanidine isothiocyanate (Interna- 
tional Biotechnologies, Inc., New Haven, CT) containing $25 \mathrm{mM} \mathrm{Na}$ citrate, $0.5 \% \mathrm{~N}$-lauryl-sarcosine, $10 \mathrm{mM}$ EDTA, $0.1 \mathrm{M}$ 2-mercaptoethanol, and $0.1 \%$ antifoam A. Homogenates were layered onto a 5.7 $\mathbf{M}$ cesium chloride (International Biotechnologies, Inc.) cushion and centrifuged for $18 \mathrm{~h}$ at $175,000 \mathrm{~g}$ at $20^{\circ} \mathrm{C}$. The RNA pellet was suspended in a solution of $25 \mathrm{mM}$ Tris- $\mathrm{HCl}, 100 \mathrm{mM}$ sodium chloride, 5 mM EDTA, and $0.1 \%$ SDS and precipitated twice in ethanol and then quantified.

Northern blot and dot blot hybridizations. For Northern blot analysis, $10 \mu \mathrm{g}$ of RNA was electrophoretically separated through a $1 \%$ agarose-2.2 $\mathrm{M}$ formaldehyde gel, and was transferred to nitrocellulose paper (Millipore Corp., Bedford, MA). After washing in 6X standard saline citrate (SSC) $(0.9 \mathrm{M}$ sodium chloride- $0.09 \mathrm{M}$ sodium citrate), the filters were dried at $80^{\circ} \mathrm{C}$ for $90 \mathrm{~min}$ and were prehybridized at $42^{\circ} \mathrm{C}$ for $18 \mathrm{~h}$ in $10 \%$ dextran sulfate, $1 \mathrm{M} \mathrm{NaCl}, 50 \%$ formamide, 2 mM EDTA, $5 \times$ Denhardts' $(0.1 \%$ Ficoll, $0.1 \%$ polyvinylpyrrolidone, $0.1 \%$ BSA) solution, and 1\% SDS. An Eco RI insert of pIL 2R2 (a generous gift of Dr. W. C. Greene, National Cancer Institute) (32) was purified by preparative electrophoresis and labeled with $\left(\alpha-{ }^{32} \mathrm{P}\right)$ deoxycytidine 5'-triphosphate (dCTP; sp act 3,000 Ci/mmol; New England Nuclear) by nick translation. The filters were hybridized overnight to the heat-denatured probe at $42^{\circ} \mathrm{C}$. Hybridization buffer was the same as prehybridization buffer except it contained $100 \mu \mathrm{g} / \mathrm{ml}$ of salmon sperm DNA. Filters were washed $\left(2 \times \operatorname{SCC}\right.$ and $1 \%$ SDS at $60^{\circ} \mathrm{C}$ for $1 \mathrm{~h}$ with constant agitation) and exposed to XAR-5 film (Kodak Laboratories, Rochester, $\mathrm{NY}$ ) at $-70^{\circ} \mathrm{C}$ with an intensifying screen.

For dot blot analysis, dilutions of total RNA in 50\% formamide6.6\% formaldehyde were applied to a Gene Screen Plus nylon membrane (New England Nuclear) using a 96-well manifold apparatus (Schleicher \& Schuell, Keene, NH). Blots were then prehybridized ( $50 \%$ formamide, $10 \%$ dextran sulfate, $1 \%$ SDS, $1 \mathrm{M} \mathrm{NaCl}$, and 100 $\mu \mathrm{g} / \mathrm{ml}$ salmon sperm DNA) and then hybridized to ${ }^{32} \mathrm{P}$-labeled IL $2 \mathrm{R}$ probe as above. Autoradiography then was performed.

Statistical analysis. Group means were compared using the $t$ test.

\section{Results}

Characteristics of PPD-induced IL 2 production by blood mononuclear cells of TB patients. PBMC or adherent cell-depleted, nylon wool-purified T cells were cultured with PPD for $48 \mathrm{~h}$. IL 2 activity of cell free supernatants then was assessed. Supernatants of PPD-stimulated PBMC from tuberculin nonreactors were devoid of IL 2 activity. PPD-induced IL 2 activity was lower in supernatants of PBMC from patients with TB (mean 2.8 \pm SE $1.4 \mathrm{U} / \mathrm{ml}$ ) as compared with healthy skin test-reactive controls $(103 \pm 30 \mathrm{U} / \mathrm{ml})$ (Fig. 1). The relative abundance of monocytes in PBMC of patients in comparison to healthy donors ( $30 \pm 8 \%$ vs. $16 \pm 2 \%$, peroxidase reactive) was

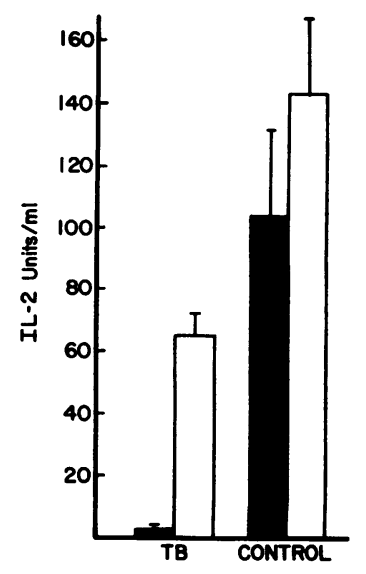

Figure 1. PPD-induced IL 2 activity of mononuclear cell supernatants of patients with TB, $(n=17$; left $)$ and healthy skin test-reactive controls ( $n$ $=17$; right). 48-h culture supernatants of PBMC (solid bar) or T cells (open bar) were assessed for IL 2 activity as mitogenesis for the IL 2-dependent cell line, CTLL-20. Units per milliliter were calculated using the probit method. insufficient to explain the discrepancy in IL 2 activity of supernatants of PBMC between the two groups (30-fold). Adherent cell depletion significantly enhanced IL 2 activity of $T$ cell supernatants in patients only $(P<0.05)$. T cell enrichment alone does not explain improved IL 2 activity of PPD-induced $T$ cell supernatants, since the observed value for IL 2 activity of PBMC (2.8 U/ml) was 10-fold lower than the value predicted if the $30 \%$ monocyte content of PBMC merely had been replaced by IL 2-producing T cells. Furthermore, in support of the active role for monocytes in depression of IL 2 activity, small numbers $(2 \%)$ of adherent monocytes from patients with tuberculosis when cocultured with autologous $T$ cells signifcantly reduced PPD-stimulated IL 2 activity (7). It should be noted, however, that mean IL 2 activity of supernatants of PPD-stimulated $T$ cells of patients remained $50 \%$ lower than that of healthy controls $(P<0.05)$. These data indicate that adherent cells from TB subjects modulate PPD-induced expression of IL 2 activity of T cells and that this is superimposed on an existing defect in IL 2 metabolism of the T cells. Modulation of IL 2 could be due to inhibition of T cell production of the growth factor by the monocytes or to binding and active metabolism of IL 2 by monocytes. These mechanisms need not, however, be mutually exclusive.

Consumption of IL 2 by adherent monocytes from TB patients. Adherent cell preparations from patients or healthy controls were incubated with purified IL $2(640 \mathrm{U} / \mathrm{ml})$ at a concentration of $1 \%$ (vol/vol). IL 2 activity of cell-free supernatants was then assessed after 24,48 , and $72 \mathrm{~h}$ of culture. IL 2 activity decreased as a function of time when adherent cells from patients but not controls were cultured with IL 2. Maximal absorption of IL 2 by monocytes occurred after $72 \mathrm{~h}$ of culture (Fig. 2). IL 2 activity of cultures of adherent cells from TB patients was one-third that of cultures containing IL 2 with no cells $(P<0.01)$, whereas IL 2 activity was not decreased significantly in the presence of monocytes from healthy donors. Moreover, supernatants of adherent cells from TB patients did not interfere with the response of the indicator cells (CTLL-20) to exogenous IL 2 (data not shown). Additionally, in three experiments, nylon wool-prepared $\mathrm{T}$ cells obtained from patients with TB were unable to absorb IL 2 significantly when cultured with IL 2 for 72 h (data not shown). Adherent cell preparations were highly enriched for monocytes, but had a small number of $\mathrm{CD}^{+}$cells (5-8\%). In some experiments, therefore, OKT3 reactive cells were removed from adherent cell populations prepared from patients by complement lysis $\left(<1 \% \mathrm{CD}^{+}\right)$. IL 2 absorbing potential of adherent cells was unaffected by depletion of $\mathrm{CD}^{+}$lymphocytes (data not shown). These data indicate that adherent monocytes from

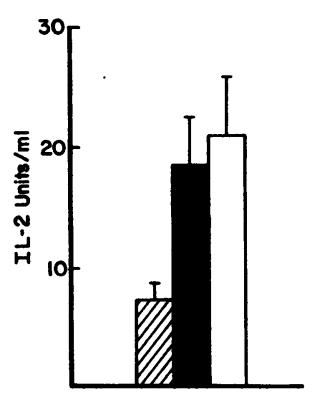

Figure 2. Depletion of IL 2 activity by adherent monocytes from TB patients. Purified IL 2 at $1 \%$ (vol/vol) was cultured with adherent cells $\left(1 \times 10^{6} / \mathrm{ml}\right)$ from patients with TB ( $n=22)$ (striped bar), healthy controls $(n=18)$ (solid bar), or cell-free $(n=18)$ (open bar); IL 2 activity of 72-h supernatants was then assessed. IL 2 activity was $7.1 \pm 1.3 \mathrm{U} / \mathrm{ml}$ (mean $\pm \mathrm{SE}$ ) in cell cultures of TB patients, $18.8 \pm 4 \mathrm{U} / \mathrm{ml}$ in cell cultures of controls, and $21 \pm 5.3 \mathrm{U} / \mathrm{ml}$ in cell-free cultures. 
Table I. Expression of IL $2 R$ on Adherent Cells Isolated from Tuberculosis Patients and Healthy Donors

\begin{tabular}{ccc}
\hline Experiment & TB patients & Healthy donors \\
\hline 1 & 10 & 4 \\
2 & 17 & 0 \\
3 & 18 & 0 \\
4 & 11 & 0 \\
5 & 57 & ND \\
6 & 60 & ND \\
7 & 33 & 7 \\
8 & 44 & 0 \\
Mean \pm SE & $30 \pm 6.4$ & $1.8 \pm 1.2^{*}$ \\
\hline
\end{tabular}

Adherent cells were assessed for expression of IL $2 R$ by indirect immunofluorescence using anti-Tac monoclonal antibody and FACS analysis. Data indicate percentage of Tac reactive cells. $N D$, not done.

$* P<0.01$.

patients with tuberculosis removed IL 2 from supernatants and imply the presence of a functional receptor for the molecule on the surface of monocytes.

Expression of IL $2 R$ by adherent monocytes from $T B$ patients. Next, freshly isolated adherent cells from TB patients and healthy PPD skin test reactive donors were examined for expression of IL 2R. Table I shows the results of FACS analysis, gaited for monocytes by size and light scatter, using antiTac antibody in eight experiments. Anti-Tac reactivity of cells from healthy donors was nil to minimal. This is not unexpected since normal peripheral blood monocytes express
IL 2R only when stimulated with cytokines (e.g., gamma-interferon) (9-11) or when exposed to bacterial products (11). In contrast, adherent cells freshly isolated from each of the TB patients were Tac reactive. Whereas the mean intensity of fluorescence of positive cells was rather uniform $(140 \pm 30$, mean $\pm S D$ ), the percentage of Tac reactivity varied considerably (10-60\%). Maintenance of IL $2 \mathrm{R}$ expression on cultured adherent cells from patients with TB was examined at 24, 48, and $72 \mathrm{~h}$ in three experiments. In two of three experiments adherent cells remained Tac reactive at the same level as fresh cells, whereas in the third experiment, Tac reactivity declined by $30 \%$.(data not shown).

Monocyte IL 2R expression was also examined by APAAP staining using anti-Tac or anti-IL 2R (2A3) antibody. This technique is more sensitive than FACS analysis and allows for the direct visualization of reactive cells. Whereas TB monocytes were consistently and strongly reactive with anti-Tac, reactivity was weak with the anti-IL $2 R$ antibody, $2 A 3$. Other studies have shown that commercial preparations of $2 \mathrm{~A} 3$ antibody do not react with monocyte IL $2 R$, although they react strongly with T cell IL $2 R$ (13). In four experiments, adherent cell preparations from TB patients were $65 \pm 5.5 \%$ (range: 48-70\%) anti-Tac positive and morphologically the reactive cells were $98 \%$ monocytes. Fig. 3 shows an example of such an experiment. Adherent cell preparations from healthy controls lacked staining when reacted with anti-Tac. Similarly patient cells were APAAP negative when reacted with control ascites containing IgG (Fig. $3 \mathrm{~A}$ ).

IL 2 binding characteristics of adherent cells of $T B$ patients. ${ }^{125}$ I-IL 2 binding was performed on adherent cells freshly isolated from TB patients or healthy PPD reactive controls. In these studies we used IL 2 concentrations that ranged from $2 \mathrm{pM}$ to $20 \mathrm{nM}$, a range that would allow assessment of
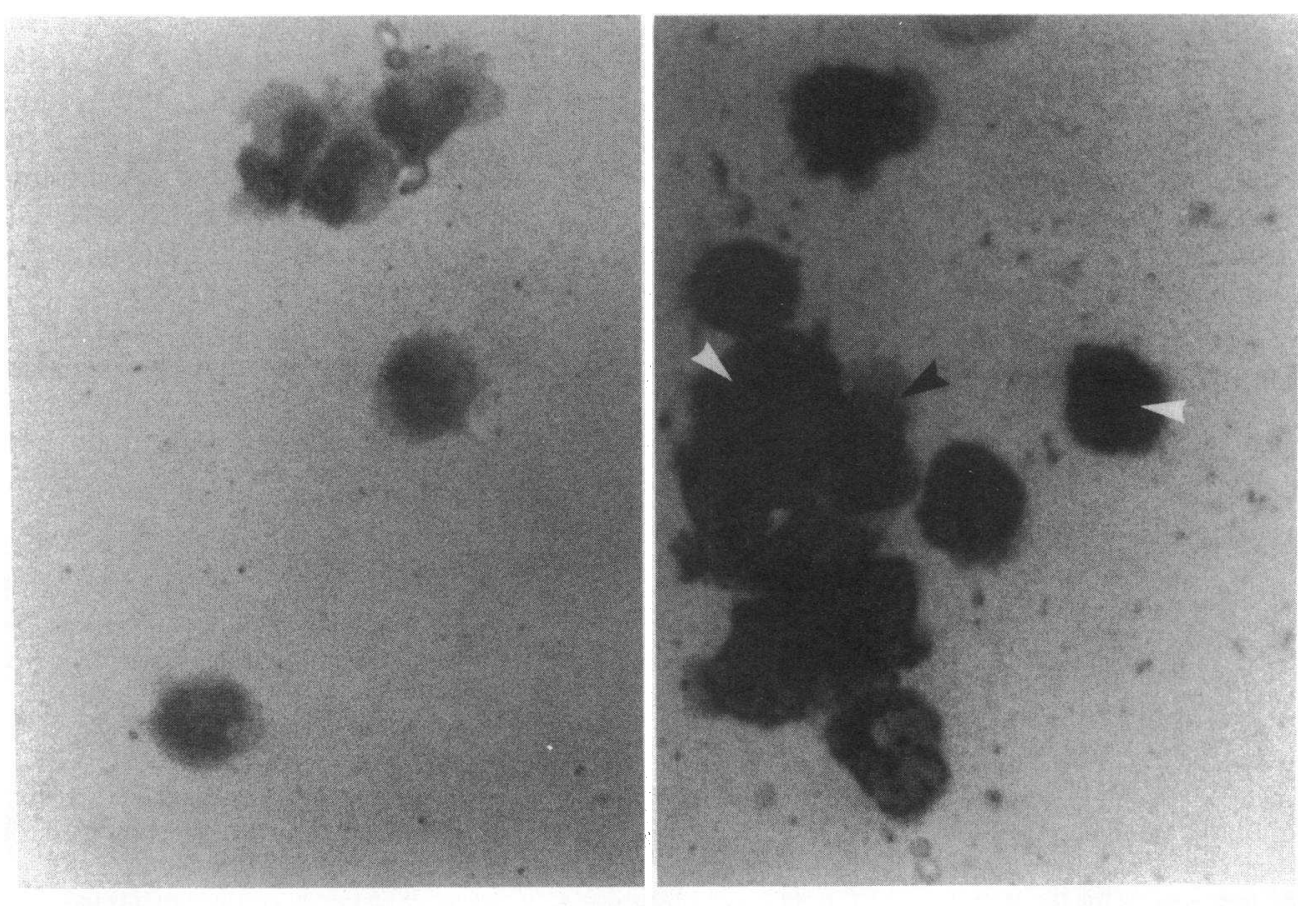

Figure 3. Cytostain of adherent cells from a TB patient with IgG in ascites $(A)$ or anti-Tac $(B)$ by APAAP technique. In $B$ black arrow shows the only nonstaining cell, white arrows point to two of the reactive (red) cells $(\times 400)$. In $A$ all cells are nonreactive. 

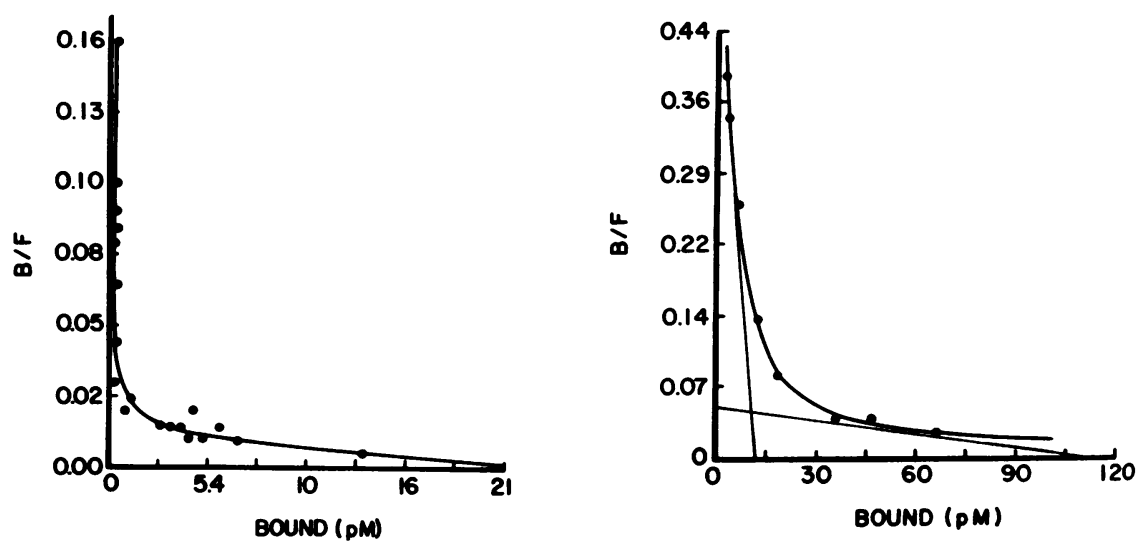

Figure 4. Scatchard analysis of ${ }^{125} \mathrm{I}-\mathrm{IL} 2$ binding to fresh adherent cells from patients with TB (left) and 72-h PHA-stimulated T cells from a healthy donor (right). The points representing actual data points and the computergenerated curves are shown. The Scatchard plot on left represents data obtained from ${ }^{125} \mathrm{I}-$ IL 2 binding of adherent cells from three patients.

both high- and low-affinity IL 2R (33). Adherent monocytes from controls did not bind the radiolabeled ligand in a specific manner. Unstimulated monocytes from TB patients demonstrated 84 high-affinity and 5,252 low-affinity binding sites per cell with respective dissociation constants $\left(K_{\mathrm{d}}\right)$ of $3.3 \mathrm{pM}$ and $1.2 \mathrm{nM}$ (Fig. 4). By comparison, T cells obtained from healthy donors and stimulated with phytohemagglutin (PHA) for $72 \mathrm{~h}$ expressed 1,800 high affinity $\left(K_{d}=20 \mathrm{pM}\right)$ and 14,455 low affinity $\left(K_{\mathrm{d}}=3 \mathrm{nM}\right)$ binding sites per cell.

Expression of IL $2 R$ RNA by adherent cells from $T B$ patients. The expression of IL $2 \mathrm{R}$ by freshly isolated adherent cells obtained from patients with active TB could potentially be secondary to adsorption of IL $2 \mathrm{R}$ on the surface of, rather

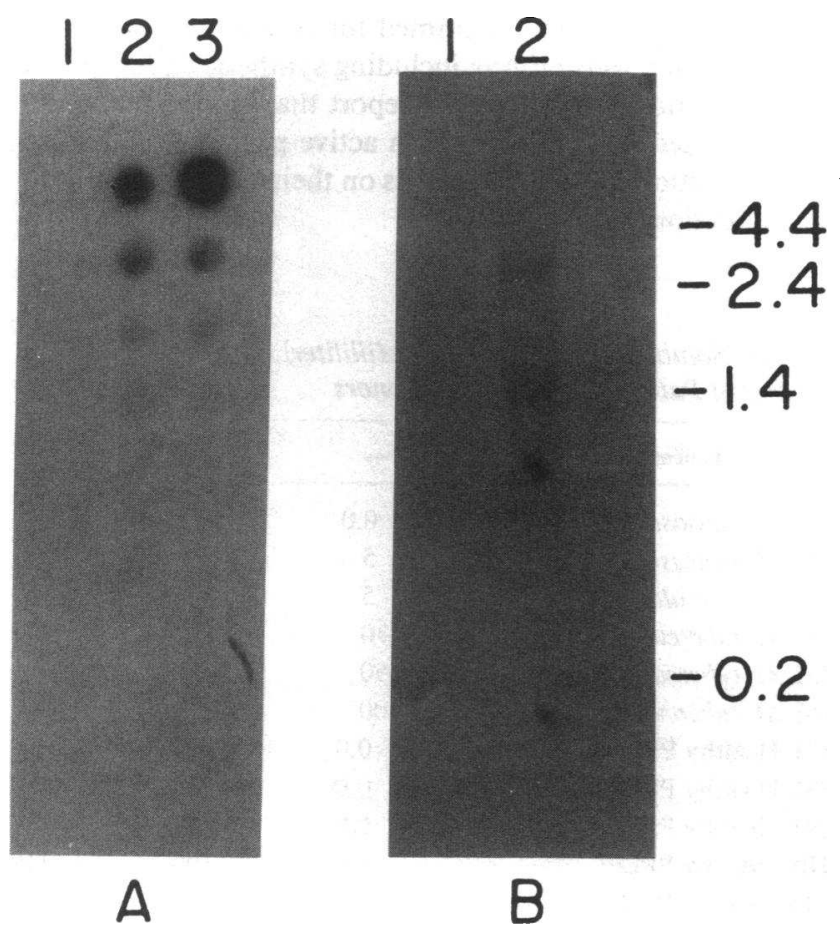

Figure 5. Analysis of total RNA hybridized with an IL 2 receptor cDNA probe encoding for the Tac protein. In $A$ total RNA extracted from fresh adherent cells of one healthy individual (lane 1 ) and two TB patients (lanes 2 and 3 ) was applied to nitrocellulose paper in dilutions ( $3 \mu \mathrm{g}$ starting dilution) by a dot-blot apparatus. $B$ is a Northern blot analysis of total RNA of unstimulated (lane 1) and PHAstimulated (lane 2) T cells. Blots were hybridized to a ${ }^{32} \mathrm{P}$-labeled Eco RI insert of pIL 2R2. RNA sizes are given in kilobases at the right of $B$. than the synthesis of, the molecule by monocytes. To assess the latter, we used a cDNA probe encoding for the Tac protein (pIL 2R2). Fig. $5 B$ shows a Northern blot analysis of total RNA extracted from resting and PHA-stimulated T cells of a healthy individual. Both the 3.5- and 1.5-kb transcripts of IL $2 \mathrm{R}$ can be seen as described previously (32). We then isolated total RNA from adherent cells of two patients with TB, one with far advanced and one with moderately advanced disease as determined by chest roentgenogram, and one skin testreactive control individual. In this experiment RNA was processed immediately after obtaining adherent cells. The amount of RNA $(6 \mu \mathrm{g})$ obtained from each individual was inadequate to perform Northern blot analysis. Dot blot analysis of RNA was performed using the IL $2 \mathrm{R}$ probe. Whereas RNA prepared from adherent cells of the two TB subjects showed strong hybridization with the probe at all dilutions, RNA from monocytes of the healthy control was inactive (Fig. $5 \mathrm{~A}$ ). These data indicate that circulating monocytes from patients are already activated to express IL 2 R. Such activation could potentially be secondary to exposure of monocytes to mycobacterial products in vivo.

Previous studies have shown that both expression of IL 1 and TNF by monocytes from healthy skin test reactors are inducible by PPD and several other mycobacterial constituents. The ability of the mycobacterial products, PPD, and a recombinant heat shock protein of Mycobacterium bovis (r65kd; a generous gift of Dr. van Embden) (34) to induce adherent cell expression of IL $2 \mathrm{R}$ was examined next. Adher-

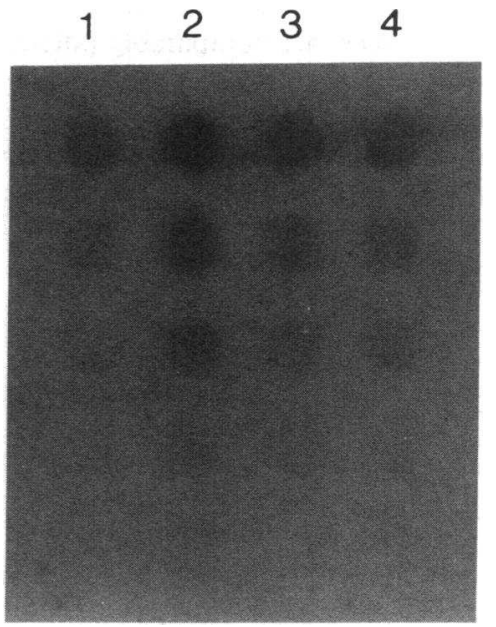

Figure 6. IL 2 receptor dot blot analysis of total RNA (in dilutions) extracted from monocytes of a PPD nonreactor in culture for $3 \mathrm{~h}$ with medium (lane 1), PPD 10 $\mu \mathrm{g} / \mathrm{ml}$ (lane 2), $65 \mathrm{kd} 10$ $\mu \mathrm{g} / \mathrm{ml}$ (lane 3), and LPS 1 $\mu \mathrm{g} / \mathrm{ml}$ (lane 4). Densitometric analysis at $0.75 \mu \mathrm{g}$ (row 3) shows a sixfold difference between lanes 1 and $2,3.5$-fold difference between lanes $l$ and 3, and 3.9-fold difference between lanes 1 and 4 . 
ent monocytes obtained from a skin test nonreactor were cultured for an additional $3 \mathrm{~h}$ in the presence or absence of stimuli $(10 \times 10$ adherent cells for each condition). Total RNA was then isolated and dot blot analysis for IL $2 R$ performed (Fig. 6). PPD induction of monocyte IL $2 R$ message was strong, whereas r65kd and LPS were comparable in this respect. A small amount of IL $2 R$ message also was seen when monocytes were left in culture without stimulatants (Fig. 6, lane 1). This could be the result of induction of IL 2R mRNA by adherence to plastic, and accumulation of the message during subsequent culturing. In comparison, RNA obtained from uncultured monocytes of the control individual (Fig. $5 A$, lane 1) was negative for IL $2 \mathrm{R}$ message.

Release of soluble IL $2 R$ in culture by adherent cells from $T B$ patients. In addition to expression of membrane IL $2 R$, a soluble released form of IL $2 \mathrm{R}$ has recently been demonstrated in supernatants of both activated T and B lymphocytes (20) and LPS or IFN stimulated monocytes. We therefore analyzed supernatants of adherent cells obtained after $72 \mathrm{~h}$ of culture from patients and healthy donors for soluble IL $2 R$ by an enzyme immunoassay. Fig. 7 shows the results for 13 TB patients and six skin test-reactive controls. Despite variable content of IL $2 R$ in culture supernatants, TB patients had a threefold higher activity as compared to controls $(P<0.05)$. Moreover, the levels of IL $2 R$ in supernatants of adherent monocytes from TB patients doubled when cells were stimulated with PPD for $72 \mathrm{~h}$ in vitro $(143 \pm 32$ to $325 \pm 47 \mathrm{U} / \mathrm{ml}$ of IL 2R; $P<0.02$ ) (Fig. 8). Three patients with newly diagnosed pulmonary infection due to mycobacteria other than $M$. $t u$ berculosis, three patients with cavitary TB, three healthy skin test nonreactors, and three healthy skin test reactors also were studied for the release of soluble IL $2 \mathrm{R}$ by adherent cell cultures. As seen in Table II, culture supernatants prepared from patients with atypical mycobacteriosis did not contain large amounts of IL 2R. Moreover PPD stimulated release of IL 2R to comparable levels in these patients and in healthy skin test reactors and nonreactors.

\section{Discussion}

Activation of circulating human peripheral blood monocytes results in the expression of the gene for IL $2 R$ followed by the appearance of IL $2 R$ on the cell surface $(11,12)$. Concomitantly, a soluble form of IL $2 \mathrm{R}$ can be identified in culture supernatants of monocytes (11). The cytokine, interferon gamma (IFN $\gamma$ ), and the bacterial products, lipopolysaccharide (LPS) and muramyl dipeptide (MDP) are comparably potent in induction of IL $2 \mathrm{R}$ on monocytes from healthy individuals; the kinetics of induction by these stimuli differ however and thus their effects are additive (12). Both superoxide generation by monocytes and cytotoxicity against the extracellular proto-

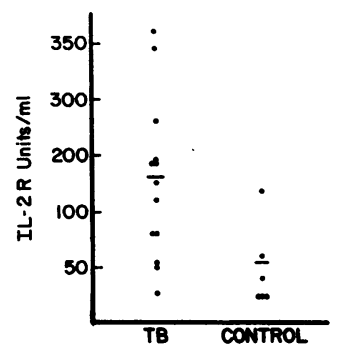

Figure 7. Soluble IL 2R levels in supernatants of adherent cells of patients with TB and skin test reactive controls. Adherent cells were cultured at 1 $\times 10^{6} / \mathrm{ml}$ for $72 \mathrm{~h}$. Cell-free supernatants were assessed for soluble IL $2 \mathrm{R}$ on a commercial ELISA assay.

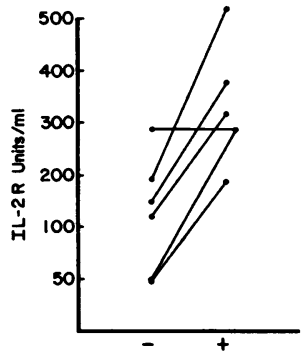

Figure 8. Soluble IL 2R levels in supernatants of PPD-stimulated (right) and unstimulated (left) adherent cells from patients with TB. 72-h culture supernatants were assessed for soluble IL $2 \mathrm{R}$ on an ELISA assay.

zoa, Giardia lamblia, are enhanced once IL 2R bearing monocytes are cocultured with IL 2 (12). Furthermore, recent studies have demonstrated that the intracellular killing of $\mathrm{Myco}$ bacterium avium complex organisms by monocytes is potentiated when IL 2 is present along with tumor necrosis factor (TNF) in cell cultures (35). These observations suggest that expression of IL $2 R$ by activated monocytes and interaction of such receptors with IL 2 might have implications in microbicidal host defenses. An alternate outcome of such an interaction, however, may be a limitation in the availability of IL 2 for $T$ cells leading to depression of $T$ cell immune responses.

This study demonstrates the spontaneous expression of IL $2 \mathrm{R}$ by circulating blood monocytes in a disease state. Alveolar macrophages obtained from patients with active pulmonary sarcoidosis display Tac positivity (13) and it has been suggested that such activated tissue macrophages may be involved in the pathogenesis of lung injury, potentially by production of oxygen radicals. In TB, previous data indicate that blood monocytes are activated or primed for activation by in vitro stimuli by numerous criteria including synthetic capacity and effector function (1-5). Here we report that blood monocytes freshly isolated from patients with active pulmonary TB also express functional IL $2 R$ molecules on their surface without in vitro induction.

Table II. Soluble IL 2R (Units per Milliliter) of Adherent Cell Cultures of Patients and Healthy Donors

\begin{tabular}{lcrr}
\hline Patient & - & PPD & LPS \\
\hline (1) M. kansasii, MA & 0.0 & 140 & - \\
(2) M. kansasii, FA & 5 & 80 & - \\
(3) M. scrofulaceum, MA & 5 & 30 & - \\
(4) M. tuberculosis MA & 170 & 550 & - \\
(5) M. tuberculosis FA & 450 & 450 & - \\
(6) M. tuberculosis MA & 300 & 530 & - \\
(7) Healthy PPD+ & 0.0 & 45 & - \\
(8) Healthy PPD+ & 0.0 & 30 & 150 \\
(9) Healthy PPD+ & 0.0 & 50 & 250 \\
(10) Healthy PPD- & 0.0 & 100 & 310 \\
(11) Healthy PPD- & 0.0 & 50 & 60 \\
(12) Healthy PPD- & 0.0 & 90 & -
\end{tabular}

Soluble IL 2R (units per milliliter) of adherent cell cultures without stimulation, or in response to $100 \mu \mathrm{g} / \mathrm{ml} \mathrm{PPD} \mathrm{or} 10 \mu \mathrm{g} / \mathrm{ml} \mathrm{LPS}$ as assessed by an enzyme immunoassay. Patients $(1-3)$ with atypical mycobacterial disease, and patients (4-6) with tuberculosis are identified by pathogen isolated and the extent of radiographic involvement (22). $F A$, far advanced; $M A$, moderately advanced. 
In our previous studies of human TB, we have shown that circulating adherent cells are suppressive both of PPD-induced IL 2 expression and blastogenesis $(6,7)$. The nature of this suppressor cell was further identified as an OKMI-reactive, nonerythrocyte rosetting, radiosensitive adherent monocyte (36). In this study, we again observed that IL 2 activity of PPD-induced PBMC supernatants was significantly lower in patients as compared to healthy controls and that removal of adherent monocytes, markedly enhanced $T$ cell supernatant IL 2 activity (Fig. 1). Absorption of purified IL 2 by adherent cells was observed in each patient (Fig. 2). This was not due to the minimal $\mathrm{T}$ cell contamination of this cell population since complement lysis of OKT3 reactive cells did not affect the IL 2 absorbing capacity of adherent cells, and nonadherent $T$ cells of patients did not remove IL 2 from culture medium. Removal of IL 2 by adherent monocytes from TB subjects would explain low IL 2 activity and low blastogenic responses of PPD-stimulated cultures of their PBMC. Metabolism of IL 2 by monocytes could not, however, be the sole basis for depressed PPD-induced T cell functions in TB for several reasons. First, some patients both in the present and in the previous studies (7) did not have a significant rise in PPD-induced IL 2 generation of their T cell cultures as compared to PBMC. Additionally, the IL 2 activity of PPD-stimulated T cells remained significantly lower in patients than in skin test reactive controls. Thus, it appears that a defect in IL 2 generation by T cells is operative in addition to the modulatory effects of monocytes. Furthermore, purified IL 2 did not correct the blastogenic defect of PBMC of patients (7). These observations argue for additional regulatory mechanisms besides IL 2 consumption by monocytes as contributing to depressed responsiveness to PPD in human infection with $M$. tuberculosis.

The presence of IL $2 R$ was confirmed on adherent cells from patients by reactivity to the monoclonal antibody, antiTac, using two techniques FACS analysis and APAAP (Table I and Figure 3). Levels of anti-Tac reactivity (mean 30\%) by FACS analysis were comparable to the reported levels of Tac expression by IFN $\gamma$ stimulated healthy monocytes (11). In this regard, APAAP cytostaining proved to be more sensitive and was useful in morphologic identification of the reactive cells, which were $98 \%$ monocytes. The affinity for binding of radioiodinated IL 2 to adherent cells from patients with tuberculosis was studied next. We found similar numbers of high affinity IL 2R (84 sites per cell) as described for dually (LPS plus IFN $\gamma$ ) stimulated monocytes from healthy donors (87 sites per cell) (11). The number of low-affinity receptors on monocytes from TB patients $(5,252$ sites per cell) was similar to LPS, or IFN $\gamma$ activated monocytes (6-7,000 sites per cell) reported previously.

It was still possible, however, that the IL $2 \mathrm{R}$ present on adherent cells from TB patients did not originate from monocytes, but were the product of another mononuclear subpopulation perhaps adsorbed to monocytes while they were in transit through the inflamed pulmonary tissues, containing activated alveolar macrophages and/or lung-recruited $\mathrm{T}$ cells. These possibilities were excluded by demonstrating expression of the gene for IL $2 \mathrm{R}$ by monocytes using a cDNA probe that encodes for the $\beta$ chain of the receptor. Thus, it appears rather, that blood monocytes from subjects with TB are activated in vivo to express IL $2 R$. This phenomenon parallels the other amplified capacities of such monocytes.

The finding of elevated soluble IL $2 R$ in supernatants of cultured adherent cells from patients with newly diagnosed TB (Fig. 7) and the further increase in levels upon stimulation with tuberculin PPD (Fig. 8) raises several interesting issues. First, it appears that in TB, similar to other pathological disorders associated with active cellular immune responses, such as sarcoidosis (17), rheumatoid arthritis (18), renal allograft rejection (37), and some lymphomas (38), soluble IL 2R may be a marker of disease activity. The cellular source of soluble IL 2R may, however, differ in these conditions. For example in sarcoidosis, it appears that both $\mathrm{T}$ cells and monocytes contribute to the content of soluble IL $2 \mathrm{R}$ in bronchoalveolar lavage (17). Second, augmentation of released IL $2 R$ in the presence of PPD might imply that enhanced soluble IL $2 \mathrm{R}$ at local sites of infection such as the pulmonary tissue could limit $\mathrm{T}$ cell responses. We have previously shown that PPD stimulates release of both IL 1 (1) and TNF (39) by monocytes. Here we report that PPD and other mycobacterial products $(65 \mathrm{kD}$ antigen) can induce monocyte IL $2 \mathrm{R}$ gene expression (Fig. 6). Thus, it is possible that direct stimulatory action of mycobacterial constituents on monocytes is a factor in the depressed response of mononuclear cells from patients with TB to PPD. Moreover, it appears that monocytes from TB patients in particular are capable of releasing significant amounts of IL $2 R$ as compared to patients with parenchymal lung disease of the same extent but due to other mycobacterial agents, again reflecting the extent of dysregulation of cellular immune parameters in human TB.

We speculate that the observed constitutive expression of functional IL $2 \mathrm{R}$ on monocytes from TB patients and the increased release of these receptors after exposure to mycobacterial products may be key factors in the phenomenon of antigen-specific suppression by adherent cells and the associated hypoergy on tuberculin skin testing (6). These phenomena and similar events conceivably occurring at local sites of infection may contribute to the immunopathogenesis of tuberculosis.

\section{Acknowledgments}

We would like to thank Dr. J. Walton Tomford for his help with obtaining blood from patients at Cleveland Metropolitan General Hospital. We appreciate Ms. Sandra Evans for her expertise in preparing this manuscript.

This research was supported by Medical Research grant from Veterans Administration and by National Institutes of Health grant AI-18571 and DK-38558 from the U. S. Public Health Service. Dr. Toossi is a recipient of an award from American Heart Association Northeast Ohio affiliate, and Dr. Sedor is an established investigator of the American Heart Association.

\section{References}

1. Fujiwara, H., M. E. Kleinhenz, R. S. Wallis, and J. J. Ellner. 1986. Increased interleukin-1 production and monocyte suppressor cell activity associated with human tuberculosis. Am. Rev. Respir. Dis. 133:73-77.

2. Ellner, J. J., P. J. Spagnuolo, and B. Z. Shacter. 1981. Augmentation of selective monocyte functions in tuberculosis. J. Infect. Dis. 144:391-397.

3. Kitahara, V., M. J. Eyre, and H. R. Hill. 1979. Monocyte function and metabolic activity in malignant and inflammatory diseases. $J$. Lab. Clin. Med. 93:472-479.

4. Tweardy, D. J., B. Z. Schacter, and J. J. Ellner. 1984. Association of altered dynamics of monocyte surface expression of human leuko- 
cyte antigen DR with immunosuppression in tuberculosis. $J$. Infect. Dis. 149:31-37.

5. Olds, G. R., J. J. Ellner, A. El Kholy, and A. A. F. Mahmoud. 1981. Monocyte mediated killing of schistosomula of Schistosoma mansoni: alterations in human schistosomiasis and tuberculosis. $J$. Immunol. 127:1538-1542.

6. Ellner, J. J. 1978. Suppressor adherent cells in human tuberculosis. J. Immunol. 121:2573-2579.

7. Toossi, Z. T., M. E. Kleinhenz, and J. J. Ellner. 1986. Defective interleukin-2 production and responsiveness in human pulmonary tuberculosis. J. Exp. Med. 163:1162-1172.

8. Meuer, S. C., R. E. Hussey, D. A. Cantrell, J. C. Hodgdon, S. F. Schlossman, K. A. Smith, and E. L. Reinhert. 1984. Triggering of the $T_{3}-T_{i}$ antigen receptor complex results in clonal $T$ cell proliferation through an interleukin-2 dependent autocrine pathway. Proc. Natl. Acad. Sci. USA. 81:1509.

9. Herrmann, F., S. A. Cannistra, H. Levine, and J. D. Griffin. 1985. Expression of interleukin-2 receptors and binding of interleukin-2 by gamma interferon-induced human leukemic and normal monocytic cells. J. Exp. Med. 162:1111-1116.

10. Holter, W., R. Grunow, H. Stockinger, and W. Knapp. 1986. Recombinant interferon- $\gamma$ induces interleukin-2 receptors on human peripheral blood monocytes. J. Immunol. 136:2171-2175.

11. Holter, W., C. K. Goldman, L. Casabo, D. L. Nelson, W. C. Greene, and T. A. Waldmann. 1987. Expression of functional IL-2 receptors by lipopolysaccharide and interferon-stimulated human monocytes. J. Immunol. 138:2917-2922.

12. Wahl, S. M., N. McCartney-Francis, D. A. Hunt, P. D. Smith L. M. Wahl, and I. M. Katona. 1987. Monocyte interleukin-2 receptor gene expression and interleukin-2 augmentation of microbicidal activity. J. Immunol. 139:1342-1347.

13. Hancock, W. W., W. A. Muller, and R. S. Cotran. 1987. Interleukin-2 receptors are expressed by alveolar macrophages during pulmonary sarcoidosis and are inducible by lymphokine treatment of normal human lung macrophages, blood monocytes, and monocyte cell lines. J. Immunol. 138:185-191.

14. Smith, K. A. 1988. The interleukin 2 receptor. Adv. Immunol. 42:165-179.

15. Robb, R. J., and W. C. Greene. 1987. Internalization of interleukin- 2 is mediated by the beta chain of the high-affinity interleukin 2 receptor. J. Exp. Med. 165:1201-1206.

16. Robb, R. J., and W. C. Greene. 1983. Direct demonstration of the identity of T-cell growth factor binding protein and the Tac antigen. J. Exp. Med. 158:1332-1337.

17. Lawrence, E. C., K. P. Broussean, M. B. Berger, C. C. Kurman, L. Marcon, and D. L. Nelson. 1988. Elevated concentration of soluble interleukin 2 receptors in serum samples and bronchoalveolar fluids in active sarcoidosis. Am. Rev. Respir. Dis. 137:759-764.

18. Symons, J. A., N. C. Wood, R. S. Di Giovine, and G. W. Duff. 1988. Soluble IL-2 receptor in rheumatoid arthritis. Correlation with disease activity, IL-1 and IL-2 inhibition. J. Immunol. 141:2612-2618.

19. Reddy, M. M., and M. H. Grieco. 1988. Elevated soluble interleukin-2 receptor levels in serum of human immunodeficiency virus infection population. AIDS Res. Hum. Retrovir. 4:115-120.

20. Rubin, L. A., C. C. Kurman, M. E. Fitz, W. E. Biddison, B. Boutin, R. Yanchoan, and D. L. Nelson. 1985. Soluble interleukin 2 receptors are released from activated human lymphoid cells in vitro. $J$. Immunol. 135:172-177.

21. Robb, R. J., and R. M. Kutny. 1987. Structure-function relationships for the IL-2 receptor system. Analysis of the sequence and ligand-binding properties of soluble Tac protein. J. Immunol. 139:855-862.
22. National Tuberculosis Association. Diagnostic standards and classification of tuberculosis. New York: the association 1961. 39-44.

23. Boyum, A. 1968. Isolation of mononuclear cells and granulocytes from human blood. Scand. J. Clin. Lab. Invest. 21(Suppl. 97):929.

24. Kaplow, L. S. 1965. Simplified mycloperoxidase staining using benzidine hydrochloride. Blood. 26:215-219.

25. Gillis, S., M. M. Ferm, W. Ou, and K. A. Smith. 1979. T cell growth factor: parameters of production and a quantiative microassay for activity. J. Immunol. 120:2027-2033.

26. Stadler, B. M., E. H. Berenstein, R. P. Siraganian, and J. J. Oppenheim. 1982. Monoclonal antibody against human interleukin-2 (IL-2). Purification of IL-2 for the production of monoclonal antibodies. J. Immunol. 128:1620-1624.

27. Uchiyama, T., S. Broder, and T. A. Waldmann. 1981. A monoclonal antibody (anti-Tac) reactive with activated and functionally mature human T-cells. J. Immunol. 126:1393-1403.

28. Cordell, J. L. 1984. Immuno enzymatic labeling of monoclonal antibodies using immune complexes of alkaline phosphatase and monoclonal alkaline phosphatase. J. Histochem. Cytochem. 32:219229.

29. Robb, R. J., P. C. Mayer, and R. Garlick. 1985. Retention of biological activity following radioiodination of human interleukin 2 : comparison with biosynthetically labeled growth factor in receptor binding assays. J. Immunol. Methods. 81:15-30.

30. Munson, P. J., and D. Rodbard. 1980. LIGAND: a versatile computerized approach for characterization of ligand-binding systems. Anal. Biochem. 107:220-239.

31. Werber, H. I., S. N. Emancipator, M. L. Tykocinski, and J. R. Sedor. 1987. The interleukin 1 gene is expressed by rat glomerular mesangial cells and is augmented in immune complex glomerulonephritis. J. Immunol. 138:3207-3212.

32. Leonard, W. J., J. M. Depper, G. R. Crabtree, S. Rudikoff, J. Pumphrey, R. J. Robb, M. Kronke, P. B. Svetlik, N. J. Peffer, T. A. Waldmann, and W. C. Greene. 1984. Molecular cloning and expression of cDNAs for the human interleukin 2 receptor. Nature (Lond.). 311:626-631.

33. Wang, H. M., and K. A. Smith. 1987. The interleukin-2 receptors: functional consequences of its bimolecular structure. J. Exp. Med. 166:1055-1069.

34. Rec, P. C., C. G. Shaar, F. C. Breedveld, W. van Eden, J. D. van Embden, I. R. Cohen, and R. R. de Vries. 1988. Synovial fluid T cell reactivity against $65 \mathrm{kD}$ heat shock protein of mycobacteria in early chronic arthritis. Lancet. 272(8609):478-480.

35. Bermudez, L. E., and L. S. Young. 1988. Tumor necrosis factor alone or in combination with IL-2, but not IFN- $\gamma$, is associated with macrophage killing of mycobacterium avium complex. J. Immunol. 140:3006-3013.

36. Kleinhenz, M. E., and J. J. Ellner. 1985. Immunoregulatory adherent cells in human tuberculosis: radition-sensitive antigen-specific suppression by monocytes. J. Infect. Dis. 152:171-176.

37. Colvin, R. B., T. C. Fuller, L. Mackeen, P. C. Kung, S. H. Ip, and A. B. Cosimi. 1987. Plasma interleukin-2 receptor levels in renal allograft recipients. Clin. Immunol. Immunopathol. 43:273-276.

38. Wagner, D. K., J. Kiwanuka, B. K. Edwards, L. A. Rubin, D. L. Nelson, and I. T. Magrath. 1987. Soluble interleukin-2 receptor levels in patients with undifferentiated and lymphoblastic lymphomas: correlation with survival. J. Clin. Oncol. 5:1262-1274.

39. Valone, S. E., E. A. Rich, R. F. Wallis, and J. J. Ellner. 1988. Expression of tumor necrosis factor in vitro by human mononuclear phagocytes stimulated with whole $\mathrm{M}$. bovis BCG and mycobacterial antigens. Infect. Immun. 56:3313-3315. 